\title{
A multi-centre pilot study of iodine status in UK schoolchildren, aged 8-10 years
}

\author{
Sarah C. Bath ${ }^{1} \cdot$ Emilie Combet $^{2} \cdot$ Patrick Scully $^{1} \cdot$ Michael B. Zimmermann $^{3}$. \\ Katharine H. C. Hampshire-Jones ${ }^{1}$ Margaret P. Rayman ${ }^{1}$
}

Received: 23 February 2015 / Accepted: 5 August 2015 / Published online: 15 August 2015

(C) The Author(s) 2015. This article is published with open access at Springerlink.com

\begin{abstract}
Purpose Iodine, as an essential constituent of thyroid hormones, is required for brain development. Iodine status is low in some UK population groups, notably in teenage girls, women of childbearing age and pregnant women. We aimed to assess iodine status of UK schoolchildren as there are no data on children below 14 years of age.

Methods Children (boys and girls) aged 8-10 years were recruited to a cross-sectional study from schools in three areas of the UK (Omagh, Northern Ireland; Glasgow, Scotland, and Guildford, South-East England). Spot urine samples, for measurement of urinary iodine concentration, were collected in the winter months (November 2012 to March 2013) and in the summer, in Omagh only (September 2013). A food frequency questionnaire was completed.

Results A total of 168 schoolchildren provided 165 urine samples. The median urinary iodine concentration was $161 \mu \mathrm{g} / \mathrm{L}$ in winter samples $(n=134)$ and $127 \mu \mathrm{g} / \mathrm{L}$ in summer samples $(n=31)$. The median urinary iodine concentration for the whole group was $144 \mu \mathrm{g} / \mathrm{L}$, weighted to account for the unequal proportion of samples from the two seasons. The children are classified as iodine-sufficient by
\end{abstract}

Margaret P. Rayman

m.rayman@surrey.ac.uk

Sarah C. Bath

s.bath@surrey.ac.uk

1 Department of Nutritional Sciences, Faculty of Health and Medical Sciences, University of Surrey, Guildford, Surrey GU2 7XH, UK

2 Human Nutrition, School of Medicine, College of Medical Veterinary and Life Sciences, University of Glasgow, Glasgow G31 2ER, UK

3 Human Nutrition Laboratory, Swiss Federal Institute of Technology (ETH), Zurich, Switzerland
WHO criteria (100-199 $\mu \mathrm{g} / \mathrm{L})$, even in the summer. Milk intake was positively associated with iodine status.

Conclusions This pilot study suggests that iodine deficiency is unlikely to be a problem in UK children aged 8-10 years. This could be a result of higher intake of milk, the principal UK dietary iodine source, in this age group than in teenagers and adults. Further assessment of iodine status in a representative sample of UK schoolchildren is required.

Keywords Iodine $\cdot$ UK $\cdot$ Children $\cdot$ Diet
Abbreviations
EAR Estimated average requirement
FFQ Food frequency questionnaire
RNI Reference nutrient intake
UIC Urinary iodine concentration
WHO World Health Organisation

\section{Introduction}

Iodine deficiency in a population is of public health concern as iodine, required for thyroid hormone (T4 and T3) production, is essential for brain and neurological development [1]. Iodine deficiency during pregnancy, infancy and childhood may have long-term implications for neurodevelopmental outcomes (e.g., cognition), as rapid brain development occurs during these periods [2]. Severe iodine deficiency is associated with goitre and cretinism [1], while even mild-to-moderate iodine deficiency during pregnancy has been associated with poorer scores for IQ, reading [3] and spelling [4]. There is also evidence that iodine supplementation may benefit older children (10-13 years) in regions of mild-to-moderate iodine deficiency as two 
randomised, placebo-controlled, trials (RCTs) demonstrated improvements in some cognitive scores $[5,6]$.

The UK iodine Reference Nutrient Intake (RNI) for children aged 7-10 years is $110 \mu \mathrm{g} /$ day [7], while the World Health Organisation (WHO) recommendation for 7- to 12 -year-olds is $120 \mu \mathrm{g}$ iodine per day [8]. For assessment of populations, the WHO recommends that spot urine samples are collected and urinary iodine concentration (UIC) is measured as it is reflective of recent iodine intake [8]. The median UIC is then compared to the criterion for iodine adequacy in a population, which is $100-199 \mu \mathrm{g} / \mathrm{L}$ for school-aged children [8].

Goitre was endemic in the UK in the nineteenth and early twentieth century, but was largely eradicated from the 1960s onwards [9]. This led to the general belief that the UK was iodine-sufficient and, until 2011, the UK was one of a few European countries that had no recent data on population iodine status (as assessed by urinary iodine concentration). However, a UK nationwide survey of over 700 schoolgirls, aged 14-15 years published in 2011 [10], revealed mild iodine deficiency (median $80.1 \mu \mathrm{g} / \mathrm{L}$ ) since which time the UK has been classified as a mildly iodinedeficient country [11].

The eradication of goitre in the UK was driven by both increased milk iodine concentration (as a result of iodine supplementation of livestock that began in the 1930s to improve reproductive performance and milk yield) and increased milk consumption in the post-war years [9]. Milk iodine concentration is relatively high in the UK (mean $300 \mu \mathrm{g} / \mathrm{L}$ ) [12], and milk and dairy products are still the major source of iodine in the UK diet, contributing up to $33 \%$ of intake in adults and $51 \%$ of intake in children aged 4-10 years, according to recent data from the National Diet and Nutrition Survey (20082012) [13]. However, there is a large seasonal variation in milk iodine content such that the concentration in winter milk is approximately double that of summer milk $[12,14]$; this has a knock-on effect on iodine status, with higher iodine intake and excretion in the winter months [10].

Although there are UK data that suggest iodine deficiency in women of childbearing age and pregnant women [15], there are no data on iodine status of children below the age of 14 years, despite the WHO recommendation that population iodine status should be assessed in school-aged children (6-12 years) [8]. The current study therefore aimed to collect data on iodine status and intake of iodine-rich foods in children aged 8-10 years from three regions of the UK: South-East England, Scotland and Northern Ireland. On the basis of data in other UK age groups, we hypothesised that children would be iodine deficient.

\section{Methods}

\section{Subjects}

Children were eligible for inclusion in the study if they were aged 8-10 years and were not taking medication for thyroid disease or using an iodine-containing supplement.

Children were recruited from three centres in the UK: Northern Ireland (Omagh), Scotland (Glasgow) and South-East England (Guildford) during the winter months (November 2012 to March 2013). These locations were chosen for the following reasons: Glasgow and Omagh as representative of the highest (Scotland) and lowest (Northern Ireland) iodine status regions in the Vanderpump et al. [10] study of UK teenage girls, while Guildford in SouthEast England was chosen as data on iodine status of women of childbearing age [16] and pregnant women [17] have already been collected in this area. Schools that were willing to participate in the study were selected from the local areas; one school in Guildford, two schools in Glasgow and three schools in Omagh were used to ensure the minimum sample size per centre $(n=30)$ was reached. In each school, a presentation was given during school assembly by one of the study team members; the purpose of this was to explain the research and protocol to the children and teachers but researchers refrained from providing information on dietary sources of iodine during the presentation.

Iodine status is known to vary by season [10], and we chose to recruit in the winter as a best case scenario-if iodine deficiency was found when milk iodine content was at its peak, deficiency would also be likely in the summer. However, the opportunity to collect samples from children in the summer months in Northern Ireland arose as part of an M.Sc. project and therefore 36 children were recruited in September 2013 (from two of the schools used in the winter cohort and an additional school) according to the same protocol as for the winter cohort. Three children in the summer cohort were excluded from analysis since they fell outside the age inclusion criterion.

The study was conducted according to the guidelines laid down in the Declaration of Helsinki, and all procedures involving human subjects were approved by the University of Surrey Ethics Committee (EC/2012/106/FHMS). As the research involved children under the age of 16 years, parents or guardians gave their written, informed, consent for the child to participate in the study.

\section{Procedure}

Study packs were distributed to the children on a Friday afternoon to take home over the weekend. These packs included a detailed information sheet for the parents (with 
contact details of the study team to enable parents to ask questions) and the consent form. The packs also contained an information sheet written for the child and an assent form that the child could complete. Parents or guardians completed a Food Frequency Questionnaire (FFQ) on behalf of their child and provided details on the child's age and sex.

The children were required to collect a urine sample before school on the Monday morning into the wide-neck $125-\mathrm{mL}$ polypropylene urine container that was provided in the study pack; we do not have information on the exact time and nature of the urine collection (i.e. whether it was the first void of the day or a fasted sample). All completed paperwork and the urine sample were then brought to the school where the packs were collected by a member of the study team. All urine samples were kept frozen (minimum $-20{ }^{\circ} \mathrm{C}$ ) until analysis.

\section{Analysis of the food frequency questionnaire}

The 23-item FFQ was designed primarily to capture information on iodine-rich foods (milk, dairy products, iodised salt, eggs and seafood), i.e. those previously identified as important contributors to iodine status in UK studies [10, 16-18]. However, it also included some questions on other food groups (i.e. fruit and vegetables, meat and poultry, starchy foods and sugary foods) to disguise which foods were iodine rich in case parents might be tempted to alter their child's diet prior to urine collection; these additional food items were not analysed in relation to urinary iodine excretion.

There were six daily frequency options for milk, as used in our previous research on pregnant women, ranging from "none" to "more than $570 \mathrm{~mL}$ " [17, 18]. For weekly egg consumption, the options were "none", "one or two", "three to six" and "more than six" per week. The FFQ also gathered data on the type of milk consumed (i.e. cows', goats', sheep's milk or soya drink) and whether organic milk was regularly used, as organic milk is known to have a lower iodine concentration than conventional milk [14]. The FFQ also asked if iodised salt was used (yes/no). This question reflected use of iodised table salt (i.e. domestic use) and was not intended to capture information on iodised salt intake from processed foods; there is minimal use of iodised salt in food manufacturer in the UK and no national iodised salt policy [19]. For all other food items, the FFQ design was based on that of the ALSPAC FFQ for children [20] and had five frequency options. The responses were assigned codes to represent weekly frequencies as follows: never/rarely $=0$; once a fortnight $=0.5$; one to three times/ week $=2$; four to seven times/week $=5.5$; once a day or more $=10$ [20]. If more than one frequency option had been ticked, the lowest frequency was chosen; food items with missing entries (seven food items had up to two missing entries) were coded to "never or rarely".

For the purposes of statistical analyses, daily milk consumption was recoded as follows: (1) $<140 \mathrm{~mL}$, (2) 140 $280 \mathrm{~mL}$, (3) $280-425 \mathrm{~mL}$, and (4) $>425 \mathrm{~mL}$; children who reported consuming soya or rice drinks were recoded to "never" for daily milk consumption so that this variable only reflected dairy milk intake. Since there were no subjects in the "more than six" category, egg consumption was collapsed into three categories (1) "none", (2) "one or two", and (3) "three to six" per week. Responses for individual dairy products (cream, yoghurts, dairy desserts, butter and cheese) and fish (white fish, oily fish and shellfish) were summed and recoded to reflect high and low intake (i.e. above or below the median). For seafood consumption, an additional category of "non-consumer" was included, which was not possible for dairy products as there were no non-consumers.

\section{Laboratory analysis}

All urine samples were shipped (on dry ice) to ETH Zürich for analysis. Urinary iodine concentration was measured in duplicate using a modification of the Sandell-Kolthoff reaction with spectrophotometric detection [21]. The coefficient of variation for UIC $( \pm \mathrm{SD})$ in the ETH laboratory is $11.5 \%$ at $31 \pm 4 \mu \mathrm{g} / \mathrm{L}$ and $3.6 \%$ at $212 \pm 8 \mathrm{~g} \mathrm{\mu g} / \mathrm{L}$. The ETH iodine laboratory participates successfully in the quality-assurance programme of the Centre for Disease Control, entitled "Ensuring the Quality of Urinary Iodine Procedures" (EQUIP) [22], using certified reference materials to ensure the accuracy of the method. Urinary creatinine concentration was measured in the biochemistry laboratory at the University Hospital, Zürich, by the Jaffe rate method.

\section{Iodine status}

The iodine status of the group was described by comparing the median UIC value with the WHO UIC cut-off for iodine adequacy in school-aged children [8]. Using urinary creatinine concentration in a spot urine sample can correct UIC for intra-individual variation in daily urine volume produced. We therefore present data as both UIC and the iodine-to-creatinine ratio.

\section{Statistical analysis}

Urinary iodine concentration and the iodine-to-creatinine ratio were not normally distributed and therefore medians with the 25th and 75th percentiles are reported. To calculate a median for the whole group, cases were weighted to account for the fact that the proportion of samples from the summer and winter seasons were unequal (18.8 and 
$81.2 \%$, respectively); an expected proportion of $50 \%$ in each season was used. UIC and the iodine-to-creatinine ratio were log-transformed using the natural logarithm to allow parametric testing.

As a result of the known seasonal variation in iodine content of milk and dairy products $[9,12]$, and the fact that the summer cohort was recruited from just one UK centre, the summer and winter cohorts were not combined for analysis of the relationship between iodine status and dietary intake. As there was only a small number of children in the summer cohort, analysis of the FFQ and effect of age and sex of the child was restricted to those recruited in the winter months $(n=133)$.

A General Linear Model was constructed using either $(\log )$ UIC or iodine-to-creatinine ratio as the dependent variable with the dietary variables (frequency of milk, dairy products, seafood, eggs and iodised salt consumption), age, gender and UK location entered as independent variables. The residuals of the model were checked for normality and homogeneity of variances was checked to ensure that these assumptions were not violated.

Significance was set at $p<0.05$ and analyses were conducted using the Statistical Package for Social Sciences (version 21.0; SPSS, Inc., Chicago, USA).

Table 1 Subject characteristics for the winter and summer cohorts

\begin{tabular}{llr}
\hline & Winter $(n=133)^{\mathrm{a}}$ & Summer $(n=33)$ \\
\hline Age (years) & & \\
8 & $37(27)$ & $15(42)$ \\
9 & $53(39)$ & $8(22)$ \\
10 & $43(32)$ & $10(28)$ \\
Sex & & \\
Boys & $68(51)$ & $20(61)$ \\
Girls & $65(49)$ & $13(39)$ \\
\hline
\end{tabular}

Figures are $n(\%)$

${ }^{a}$ Two children did not return the questionnaire

\section{Results}

A total of 168 children participated in the study and 165 provided a urine sample of which $134(81.2 \%)$ were in winter and $31(18.8 \%)$ in summer. Of the 135 children recruited in the winter ( 52 from Guildford; 53 from Glasgow; and 30 from Omagh), one child just returned a questionnaire, and 132 children provided both urine and questionnaire data. Of the 33 eligible children recruited in the summer (all from Omagh), 31 children provided both a urine sample and questionnaire data.

The subject characteristics for each season are shown in Table 1. There was no significant difference in the percentage of boys and girls or the proportion of children in each age category (i.e. 8, 9 or 10 years) between the three UK centres $(p=0.27$ and $p=0.09$, respectively). There was also no significant difference in milk $(p=0.23)$, seafood $(p=0.29)$, dairy product $(p=0.56)$ or egg $(p=0.27)$ consumption between centres.

\section{Iodine status}

The urinary iodine concentration and iodine-to-creatinine ratio are summarised in Table 2. Based on the overall (weighted) median UIC of $144 \mu \mathrm{g} / \mathrm{L}$ and the fact that just $4.2 \%(n=7)$ had a UIC below $50 \mu \mathrm{g} / \mathrm{L}$, the group is classified as having adequate iodine status according to $\mathrm{WHO} /$ UNICEF/ICCIDD criteria [8]. UIC was below $100 \mu \mathrm{g} / \mathrm{L}$ in 40 samples $(24 \%)$ and above $300 \mu \mathrm{g} / \mathrm{L}$ in 23 samples $(14 \%)$.

The samples collected during the summer $(n=31)$ had lower median UIC (127 vs. $161 \mu \mathrm{g} / \mathrm{L}$ ) and iodine-to-creatinine ratio (143 vs. $157 \mu \mathrm{g} / \mathrm{g}$ ) than those collected in the winter ( $n=134$; Table 2$)$; when comparing summer and winter samples from Northern Ireland, the difference was significant for UIC $(p=0.03)$ but not for the iodine-to-creatinine ratio $(p=0.65)$. Nevertheless, the median UIC was above the cut-off for iodine adequacy $(100 \mu \mathrm{g} / \mathrm{L})$ even in
Table 2 Urinary iodine concentration and urinary iodine-to-creatinine ratio, split by season of recruitment

\begin{tabular}{|c|c|c|c|c|c|}
\hline \multirow[t]{2}{*}{ Season } & \multirow[t]{2}{*}{ Location } & \multicolumn{2}{|c|}{ Iodine concentration $(\mu \mathrm{g} / \mathrm{L})$} & \multicolumn{2}{|c|}{$\begin{array}{l}\text { Iodine-to-creatinine } \\
\text { ratio }(\mu \mathrm{g} / \mathrm{g})\end{array}$} \\
\hline & & $n$ & Median (IQR) & $n$ & Median (IQR) \\
\hline Both seasons & $\mathrm{All}^{\mathrm{a}}$ & 165 & $144(95-223)$ & $164^{\mathrm{b}}$ & $150(102-202)$ \\
\hline \multirow[t]{4}{*}{ Winter } & All & 134 & $161(105-253)$ & $133^{\mathrm{b}}$ & $157(101-228)$ \\
\hline & SE England & 51 & $142(85-197)$ & 51 & 134 (91-182) \\
\hline & Scotland & 53 & $171(131-254)$ & $52^{\mathrm{b}}$ & $188(123-271)$ \\
\hline & $\mathrm{N}$ Ireland & 30 & $196(111-347)$ & 30 & $142(85-255)$ \\
\hline Summer & $\mathrm{N}$ Ireland & 31 & $127(93-164)$ & 31 & $143(102-193)$ \\
\hline
\end{tabular}

${ }^{a}$ Cases weighted to account for unequal proportion of summer and winter samples (18.8 and $81.2 \%$, respectively)

${ }^{\mathrm{b}}$ Insufficient urine volume for measurement of urinary creatinine concentration in one sample 
Fig. 1 Urinary iodine concentration of UK schoolchildren (8-10 years); dark and pale bars represent results from samples collected in the winter and summer seasons, respectively. Black horizontal bars illustrate the lower and upper limits of the WHO adequate range for median iodine concentration in spot urine samples from a population of schoolchildren $(100-199 \mu \mathrm{g} / \mathrm{L})[8]$

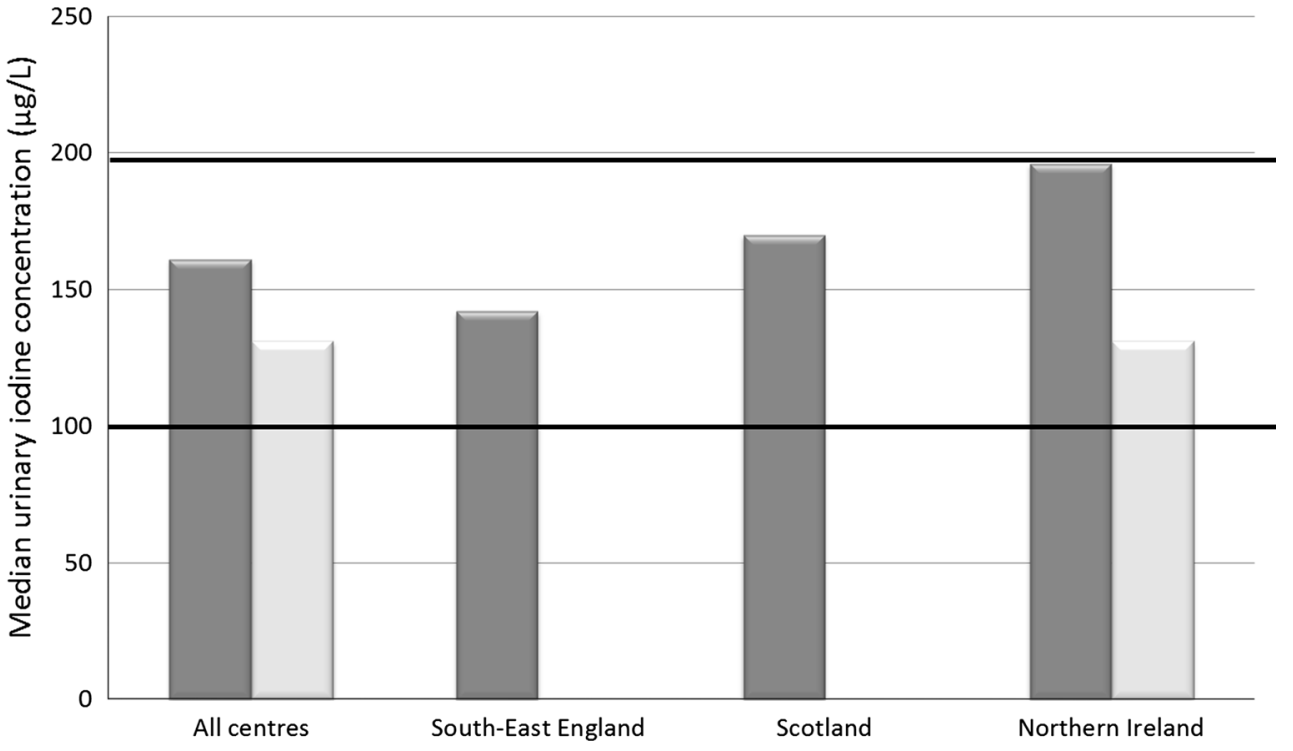

the summer months. In the summer cohort, $33 \%$ of children $(n=11)$ had a UIC below $100 \mu \mathrm{g} / \mathrm{L}$ compared to $22 \%$ $(n=29)$ in the winter cohort.

In the winter cohort, there was a significant difference in UIC $(p=0.04)$ and iodine-to-creatinine ratio $(p=0.009)$ between UK centres, although the pattern was not consistent between the two measures of iodine status; children in Northern Ireland had a higher UIC than the other centres, whereas those in Scotland had a higher iodine-to-creatinine ratio (Table 2; Fig. 1).

Neither UIC nor the iodine-to-creatinine ratio was significantly associated with age in the samples collected during the winter ( $p=0.71$ and $p=0.69$, respectively). In winter samples, the median UIC was not significantly different in girls and boys (157 vs. $169 \mu \mathrm{g} / \mathrm{L}$ respectively, $p=0.81$, nor was the median iodine-to-creatinine ratio (152 vs. $163 \mu \mathrm{g} / \mathrm{g}$, respectively, $p=0.70$ ). The number of samples collected in the summer was too small to stratify iodine results by age or sex.

\section{Relationship between diet and iodine status in the winter cohort}

The relationship between dietary intake and urinary iodine excretion was explored for the 132 children who provided both a urine sample and questionnaire data (winter cohort only; Table 3).

In univariate analyses, milk intake was positively associated with both UIC and iodine-to-creatinine ratio ( $p=0.006$ and $p=0.005$, respectively). Median UIC increased with higher milk consumption (Table 3) and a Bonferroni post hoc test revealed that children who consumed $<140 \mathrm{~mL}$ per day had significantly lower UIC than those who consumed 140-280 $\mathrm{mL}(p=0.03)$ and $>425 \mathrm{~mL}$
( $p=0.008$ ). Similarly those children consuming $<140 \mathrm{~mL}$ had significantly lower iodine-to-creatinine ratio than those consuming 140-280 mL ( $p=0.004)$; all other post hoc comparisons were non-significant.

The majority of the children consumed cows' milk (96.2\%), two consumed goats' milk (1.5\%), two consumed soya drinks $(1.5 \%)$ and one child consumed a rice drink $(0.8 \%)$. A one-way ANOVA showed that there was a significant difference in UIC between the type of milk, or milk substitute, consumed $(p=0.006)$ and the post hoc test revealed that soya and rice drink consumers (combined) had significantly lower iodine status than those who consumed cows' milk ( $p=0.02$ ) or goats' milk ( $p=0.006)$. Organic milk was normally consumed by $14.4 \%$ of children $(n=19)$ but their UIC or iodine-to-creatinine ratio was not significantly different to those of other children ( $p=0.37$ and 0.41 , respectively).

There was no significant difference in either UIC or iodine-to-creatinine ratio between high and low consumption of other dairy products $(p=0.90$ and $p=0.21$, respectively) or between categories of egg consumption ( $p=0.98$ and $p=0.37$ respectively). Though non-consumers of seafood had a lower iodine status than consumers (Table 3), the differences were not significant for either UIC $(p=0.14)$, or iodine-to-creatinine ratio $(p=0.49)$. Just 17 $(12.9 \%)$ children were consumers of iodised salt and their UIC and iodine-to-creatinine ratio was not significantly different to those of non-consumers.

We used a General Linear Model to explore the associations between diet (intake of milk, dairy products, eggs, seafood and iodised salt), age, gender and UK geographical location (three centres) and both UIC and iodineto-creatinine ratio. The model explained only $12.1 \%$ of the variation in UIC and $11.6 \%$ of the variation in 
Table 3 Unadjusted associations between dietary habits and urinary iodine excretion (iodine concentration and iodine-to-creatinine ratio); analysis restricted to the winter cohort only

\begin{tabular}{|c|c|c|c|c|c|c|c|}
\hline \multirow[t]{2}{*}{ Food group } & \multirow[t]{2}{*}{ Category } & \multicolumn{3}{|c|}{ Urinary iodine concentration $(\mu \mathrm{g} / \mathrm{L})$} & \multicolumn{3}{|c|}{ Iodine-to-creatinine ratio $(\mu \mathrm{g} / \mathrm{g})$} \\
\hline & & $N(\%)$ & Median (IQR) & $P^{\mathrm{a}}$ & $N(\%)$ & Median (IQR) & $P^{\mathrm{a}}$ \\
\hline \multirow[t]{4}{*}{$\operatorname{Milk}(\mathrm{mL} / \mathrm{day})^{\mathrm{b}}$} & $<140$ & $37(28.0)$ & $134(87-164)$ & 0.006 & $37(28.2)$ & $117(74-173)$ & 0.005 \\
\hline & $140-280$ & $46(34.8)$ & $165(100-282)$ & & $46(35.1)$ & $195(117-276)$ & \\
\hline & $280-425$ & $24(18.2)$ & $180(143-264)$ & & $23(17.6)$ & $150(112-238)$ & \\
\hline & $>425$ & $25(18.9)$ & $227(146-286)$ & & $25(19.1)$ & $168(129-216)$ & \\
\hline \multirow[t]{2}{*}{ Dairy products (freq/week) } & $<14$ & $67(50.8)$ & $154(102-264)$ & 0.90 & $66(50.4)$ & $164(111-256)$ & 0.21 \\
\hline & $\geq 14$ & $65(49.2)$ & $163(129-237)$ & & $65(49.6)$ & $149(100-213)$ & \\
\hline \multirow[t]{3}{*}{ Eggs (number/week) } & None & $23(17.4)$ & $147(94-253)$ & 0.98 & $23(17.6)$ & $124(108-206)$ & 0.37 \\
\hline & One/Two & $85(64.4)$ & $163(109-244)$ & & $84(64.1)$ & $165(111-225)$ & \\
\hline & Three-six & $24(18.2)$ & $176(109-254)$ & & $24(18.3)$ & $177(78-265)$ & \\
\hline \multirow[t]{3}{*}{ Seafood (times/week) } & None & $6(4.5)$ & $102(34-172)$ & 0.14 & $6(4.6)$ & $118(98-184)$ & 0.49 \\
\hline & $\leq 2$ & $58(43.9)$ & $168(13-272)$ & & $57(43.5)$ & $139(92-216)$ & \\
\hline & $>2$ & $68(51.5)$ & $157(102-227)$ & & $68(51.9)$ & $166(111-246)$ & \\
\hline \multirow[t]{2}{*}{ Consumer of iodised salt } & Yes & $17(12.9)$ & $146(83-287)$ & 0.52 & $16(12.2)$ & $165(78-237)$ & 0.99 \\
\hline & No & $115(87.1)$ & $163(116-245)$ & & $115(87.8)$ & $162(109-227)$ & \\
\hline
\end{tabular}

${ }^{\text {a }}$ Results from independent $t$ test (dairy products and iodised salt) or ANOVA on the log-transformed UIC or iodine-to-creatinine ratio data

b Consumers of soya and rice drinks recoded to "none" for dairy milk intake

iodine-to-creatinine ratio. Both milk intake and seafood were significantly, and positively, associated with UIC ( $p=0.007$ and $p=0.005$, respectively). No other potential predictors of UIC were significant in the model. By contrast, the only significant predictors of iodine-to-creatinine ratio were milk intake $(p=0.002)$ and UK centre $(p=0.01)$; post hoc analysis revealed that Glasgow had the highest iodine-to-creatinine ratio, which was significantly higher than in Guildford $(p=0.01)$ but not significantly higher than in Omagh $(p=0.09)$.

\section{Discussion}

The results of this cross-sectional pilot study provide the first data for iodine status in UK children aged 8-10 years and, contrary to our hypothesis, suggest that this age group is iodine replete. These findings contrast with those of iodine deficiency in other UK population groups, namely teenage school-girls [10], pregnant women [17, 23-25] and women of child-bearing age $[16,26]$. Our weighted median UIC from both winter and summer cohorts and from both boys and girls $(144 \mu \mathrm{g} / \mathrm{L})$ cannot easily be compared with the median UIC of teenage schoolgirls $(80.1 \mu \mathrm{g} / \mathrm{L})$ as that value was not weighted and most $(72.8 \%)$ of the girls were recruited in the summer [10] which would have resulted in a lower median UIC owing to the lower iodine content of summer milk [12]. However, when comparisons are restricted to samples collected from girls in the winter, our median value is 1.7 times higher than that of UK teenage girls (157 vs. $95.1 \mu \mathrm{g} / \mathrm{L}$ ) [10], suggesting that the children in the current study have considerably higher iodine status than UK teenage girls.

The fact that the children in our study are iodine-sufficient may be the result of higher milk consumption in school-aged children than in adults and teenagers, who have been the subject of previous UK iodine surveys [10, 16, 17, 23-26]. Children in the present study reported a higher intake of milk than in our studies of pregnant women; $37 \%$ of children consumed more than $280 \mathrm{~mL}$ milk per day, compared to $28 \%$ of pregnant women in Surrey [17] and $33 \%$ of pregnant women in Oxford [18]. This observation is supported by data from the most recent (2008/09-2011/12) National Diet and Nutrition Survey (NDNS) where reported daily milk intake (from food diary analysis) is higher in children aged 4-10 years (average $198 \mathrm{~g} /$ day) than those aged 11-18 (average $142 \mathrm{~g} /$ day) or in adults aged 19-64 years (average $136 \mathrm{~g} /$ day) [13].

Our results support the view that iodine status in schoolchildren should not be used as a proxy for all population groups within a country [27, 28], as has been recommended in the past [29]. This is particularly true in countries such as the UK where the main sources of iodine are milk and dairy produce which are consumed in high quantities by children but not necessarily by other age groups; children are not a representative group with respect to intake of iodine-rich foods and would therefore present a biased estimate of population status. There is evidence that milk 
consumption tends to decline with advancing age [30], such that milk will contribute less to total iodine intake in adults; thus adults who consume less milk will be more at risk of iodine deficiency than children in the same country. The UK would be classified as iodine-sufficient if the results of this study were used instead of those from the study of teenage girls [10]. However, this would mask the extent of deficiency in the UK, particularly in pregnant women and women of childbearing age, who are vulnerable to the effects of iodine deficiency. However, it is important to keep in mind the fact that the published cutoffs to assess iodine status in adults and pregnant women have not been validated and thus describing population status in these vulnerable groups is perhaps more challenging than in school-aged children, where more research has been conducted and the cut-offs are evidence-based [29].

It is important to highlight the fact that although our results suggest that UK school-aged children are iodine-sufficient, this does not detract from the potential public health implications of iodine deficiency in UK pregnant women $[17,23-25]$. This is suggested by a recent Australian study [4] that found an association between iodine deficiency in pregnancy and poorer scores for spelling and grammar in the offspring at age 9, despite the fact that the children had grown up in an iodine-sufficient environment (they were born at the time of a local voluntary programme of iodine fortification of bread) [4]. During pregnancy, there are critical developmental windows in which iodine deficiency may lead to irreversible adverse brain effects that cannot be overcome by later iodine sufficiency. During childhood, cognitive impairment due to iodine deficiency appears to be at least partly reversible as shown in two randomised placebo-controlled trials in mild-to-moderate iodine-deficient school-aged children [5, 6], where iodine supplementation improved performance on some, though not all, cognitive tests. Hence iodine deficiency in UK pregnant women may have negative consequences on offspring cognition, even if UK children are ingesting adequate iodine, though further research in this area is required.

Our results showed that there were significant differences in iodine status between the three recruitment centres, but all had a median UIC within the optimum range as defined by WHO et al. [8]. In the nationwide study of iodine status in teenage schoolgirls, Vanderpump and colleagues found that the lowest UIC was in Northern Ireland (Belfast), whereas we found the opposite in our study which showed the highest UIC in Omagh, Northern Ireland. When using the iodine-to-creatinine ratio, children in Scotland had the highest median value which supports the finding by Vanderpump et al. of the highest UIC values being in Scotland. The discrepancy between the results by centre for UIC and iodine-to-creatinine ratio cannot be explained but may reflect variation as a result of the relatively small numbers of children in each centre (e.g., 30 children in Omagh); hence, the results for each centre should not be interpreted in isolation but should be used to contribute to the overall median for children aged $8-10$ years in the UK.

Creatinine adjustment of UIC is not recommended by the WHO, owing to concerns that malnutrition results in low creatinine excretion and can thus mask iodine deficiency [8]. However, malnutrition is not likely to be a concern in the UK and we have previously found that use of the iodine-to-creatinine ratio (rather than UIC) in samples collected from pregnant women improves the ability to relate iodine status either to child outcomes [3] or dietary intake $[17,18]$. In the present study, it was not clear that creatinine adjustment improved the relationship with dietary intake. As we did not collect 24-h urine samples, it is difficult to estimate which measure is preferable in the estimate of iodine status in this UK age group. In adults there are published reference values for the expected 24-h urinary creatinine excretion according to age and sex of the individual, enabling estimation of 24-h iodine excretion, which has been shown to be superior to UIC and the crude iodine-to-creatinine ratio [31-33]. However, as children are still growing, which affects muscle mass and thus creatinine excretion [34], information in addition to age and sex may be required for more accurate use of the iodine-tocreatinine ratio; published data for expected 24-h creatinine excretion in children require anthropometric measurements (height and/or weight) [35], and unfortunately, these data were not available for this cohort. Therefore, we present results for both measures of iodine status but further study is required to evaluate the usefulness of the iodine-to-creatinine ratio in well-nourished children.

As in other UK studies [10, 16, 17], and those in Europe [36], milk intake was positively associated with iodine status, even after adjustment for other factors. The UIC of consumers of soya/rice drinks $(n=3)$ was significantly lower than that of cows' or goats' milk drinkers. Most soya and rice drinks available in the UK are not fortified with iodine and therefore are a poor source of iodine [37]. Children who regularly drink soya milk in preference to cows' milk may be at risk of iodine deficiency, but the small number of consumers in this cohort means that firm conclusions cannot be drawn. Reflecting the high concentration of iodine in seafood [38], we found that non-consumers of seafood had lower iodine status than children who consumed some seafood, though this was only significant in the model for UIC and not for the iodine-to-creatinine ratio. Our results suggest that a diet that includes a regular intake of fish, milk and dairy products will help to ensure adequate iodine intake. Our study was too small to explore dietary patterns that may result in iodine deficiency, for example children who largely follow a milk-free diet. 
The strengths of the present study include the fact that this is the first report of iodine status in this age group and has collected data from three regions of the UK, and in both seasons (for one location). However, we acknowledge that there are several limitations, including the fact that the sample size is relatively small (particularly for the summer season); however, according to the estimations by Andersen et al. [39], our overall sample size is above that required $(n=125)$ to estimate the iodine level in a population with $95 \%$ confidence within a precision range of $10 \%$. Another limitation of the study is the fact that only spot urine samples were collected and while this is the WHO-recommended method for assessing population iodine status [8], it gives us no opportunity to explore whether the higher iodine status in this age group is as a result of lower total urine volume than in teenagers or adults, which has recently been suggested as a reason that age-specific cut-offs to indicate iodine sufficiency are required [40]. It would be interesting to compare the 24-h iodine excretion, as a hydration-independent measure, in UK children and women of childbearing age to evaluate whether the higher iodine status in children is confirmed after accounting for total urine volume.

In conclusion, our results suggest 8- to 10-year-old children in the UK have sufficient iodine intake, in contrast to recent findings from female teenagers and pregnant and non-pregnant women that suggest deficiency in these groups. This is a different situation to other countries, for example New Zealand, where iodine deficiency was demonstrated in children [41], adults [42] and pregnant women [43]. As a result of mild iodine deficiency, a national iodine fortification programme was introduced in New Zealand (and Australia) in 2009 [44]; if such a programme were to be introduced in the UK, careful consideration would need to be given to the effect that raising iodine status would have on children who are already iodine replete (by WHO criteria [8]). A recent Australian report details the change in urinary iodine concentration in children after introduction of the fortification programme but does not include information on effect on thyroid or other health outcomes in the children from regions with adequate iodine status at baseline [45]. In view of the relatively small number of children in our study, further investigation in a representative sample of UK schoolchildren is required before public health recommendations for the UK can be made.

\footnotetext{
Acknowledgments We are grateful to all the children and families who participated in this study and to Laura Matthews and Dr Jinyuan Mao for assistance with study pack assembly and distribution. We thank Dr Maria Andersson and Sara Stinca, ETH Zürich, for laboratory analysis of the urine samples.
}

Authorship S.C.B and M.P.R designed the study. S.C.B, M.P.R, E.C and P.S recruited the subjects. M.B.Z was responsible for the laboratory analysis of the urine samples. K.H.-J. coded the food frequency questionnaires. S.C.B and K.H.-J analysed the data. S.C.B wrote the first draft of the manuscript and all authors revised and approved the final version.

\section{Compliance with ethical standards}

Financial support S.C.B. was supported by an MRC Population Health Scientist Fellowship (Grant reference MR/K02132X/1).

Conflict of interest We declare that we have no conflict of interest.

Open Access This article is distributed under the terms of the Creative Commons Attribution 4.0 International License (http://creativecommons.org/licenses/by/4.0/), which permits unrestricted use, distribution, and reproduction in any medium, provided you give appropriate credit to the original author(s) and the source, provide a link to the Creative Commons license, and indicate if changes were made.

\section{References}

1. Zimmermann MB (2009) Iodine deficiency. Endocr Rev 30(4):376-408

2. Williams GR (2008) Neurodevelopmental and neurophysiological actions of thyroid hormone. J Neuroendocrinol 20(6):784-794

3. Bath SC, Steer CD, Golding J, Emmett P, Rayman MP (2013) Effect of inadequate iodine status in UK pregnant women on cognitive outcomes in their children: results from the Avon Longitudinal Study of Parents and Children (ALSPAC). Lancet 382(9889):331-337. doi:10.1016/s0140-6736(13)60436-5

4. Hynes KL, Otahal P, Hay I, Burgess JR (2013) Mild iodine deficiency during pregnancy is associated with reduced educational outcomes in the offspring: 9-year follow-up of the gestational iodine cohort. J Clin Endocrinol Metab 98(5):1954-1962. doi: $10.1210 /$ jc. $2012-4249$

5. Gordon RC, Rose MC, Skeaff SA, Gray AR, Morgan KM, Ruffman $T$ (2009) Iodine supplementation improves cognition in mildly iodine-deficient children. Am J Clin Nutr 90(5):1264-1271

6. Zimmermann MB, Connolly K, Bozo M, Bridson J, Rohner F, Grimci L (2006) Iodine supplementation improves cognition in iodine-deficient schoolchildren in Albania: a randomized, controlled, double-blind study. Am J Clin Nutr 83(1): 108-114

7. Department of Health (1991) Report on health and social subjects: 41. Dietary reference values for food, energy and nutrients for the United Kingdom. The Stationery Office, London

8. WHO, Unicef, ICCIDD (2007) Assessment of iodine deficiency disorders and monitoring their elimination. WHO, Geneva

9. Phillips DI (1997) Iodine, milk, and the elimination of endemic goitre in Britain: the story of an accidental public health triumph. J Epidemiol Commun Health 51(4):391-393

10. Vanderpump MP, Lazarus JH, Smyth PP, Laurberg P, Holder RL, Boelaert K, Franklyn JA (2011) Iodine status of UK schoolgirls: a cross-sectional survey. Lancet 377(9782):2007-2012

11. Andersson M, Karumbunathan V, Zimmermann MB (2012) Global iodine status in 2011 and trends over the past decade. $\mathbf{J}$ Nutr 142:744-750

12. Food Standards Agency (2008) Retail survey of iodine in UK produced dairy foods. FSIS 02/08. http://tna.europarchive. org/20140306205048. http://www.food.gov.uk/science/research/ surveillance/fsisbranch2008/fsis0208. Accessed 29 April 2015

13. Bates B, Lennox A, Prentice A, Bates C, Page P, Nicholson SK, Swan G (2014) National Diet and Nutrition Survey, results from years 1-4 of the rolling programme. www.gov.uk/government/ 
uploads/system/uploads/attachment_data/file/310995/NDNS_ Y1_to_4_UK_report.pdf

14. Bath SC, Button S, Rayman MP (2012) Iodine concentration of organic and conventional milk: implications for iodine intake. $\mathrm{Br}$ J Nutr 107(7):935-940

15. Bath SC, Rayman MP (2015) A review of the iodine status of UK pregnant women and its implications for the offspring. Environ Geochem Health 37:619-629

16. Bath SC, Sleeth ML, McKenna M, Walter A, Taylor A, Rayman MP (2014) Iodine intake and status of UK women of childbearing age recruited at the University of Surrey in the winter. Br J Nutr 112(10):1715-1723

17. Bath SC, Walter A, Taylor A, Wright J, Rayman MP (2014) Iodine deficiency in pregnant women living in the South East of the UK: the influence of diet and nutritional supplements on iodine status. Br J Nutr 111(9):1622-1631

18. Bath S, Furmidge-Owen V, Redman CWG, Rayman MP (2015) Gestational changes in iodine status in a cohort study of UK pregnant women: season as an effect modifier. Am J Clin Nutr 101:1180-1187

19. Bath S, Button S, Rayman MP (2014) Availability of iodised table salt in the UK-is it likely to influence population iodine intake? Public Health Nutr 17(2):450-454

20. Cribb V, Emmett P, Northstone K (2013) Dietary patterns throughout childhood and associations with nutrient intakes. Public Health Nutr 16(10):1801-1809. doi:10.1017/ s1368980012004132

21. Pino S, Fang SL, Braverman LE (1996) Ammonium persulfate: a safe alternative oxidizing reagent for measuring urinary iodine. Clin Chem 42(2):239-243

22. Caldwell KL, Makhmudov A, Jones RL, Hollowell JG (2005) EQUIP: a worldwide program to ensure the quality of urinary iodine procedures. Accred Qual Assur 10:356-361

23. Barnett C, Visser T, Williams F, Toor H, Duran S, Presas M, Morreale de Escobar G, Hume R (2002) Inadequate iodine intake of $40 \%$ of pregnant women from a region in Scotland. J Endocrinol Invest 25:(Supp. No. 7):90

24. Kibirige MS, Hutchison S, Owen CJ, Delves HT (2004) Prevalence of maternal dietary iodine insufficiency in the north east of England: implications for the fetus. Arch Dis Child Fetal Neonatal Ed 89(5):F436-F439

25. Pearce EN, Lazarus JH, Smyth PP, He X, Dall'amico D, Parkes AB, Burns R, Smith DF, Maina A, Bestwick JP, Jooman M, Leung AM, Braverman LE (2010) Perchlorate and thiocyanate exposure and thyroid function in first-trimester pregnant women. J Clin Endocrinol Metab 95(7):3207-3215

26. Lampropoulou M, Lean M, Combet Aspray E (2012) Iodine status of women of childbearing age in Scotland. Proc Nutr Soc 71:E143

27. Caldwell KL, Makhmudov A, Ely E, Jones RL, Wang RY (2011) Iodine status of the U.S. population, National Health and Nutrition Examination Survey, 2005-2006 and 2007-2008. Thyroid 21(4):419-427

28. Pearce EN, Andersson M, Zimmermann M (2013) Global iodine nutrition-where do we stand in 2013? Thyroid. doi:10.1089/ thy. 2013.0128

29. Zimmermann MB, Andersson M (2012) Assessment of iodine nutrition in populations: past, present, and future. Nutr Rev 70(10):553-570. doi:10.1111/j.1753-4887.2012.00528.x

30. Dror DK, Allen LH (2014) Dairy product intake in children and adolescents in developed countries: trends, nutritional contribution, and a review of association with health outcomes. Nutr Rev 72(2):68-81. doi:10.1111/nure.12078
31. Knudsen N, Christiansen E, Brandt-Christensen M, Nygaard B, Perrild H (2000) Age- and sex-adjusted iodine/creatinine ratio. A new standard in epidemiological surveys? Evaluation of three different estimates of iodine excretion based on casual urine samples and comparison to $24 \mathrm{~h}$ values. Eur J Clin Nutr 54(4):361-363

32. Konig F, Andersson M, Hotz K, Aeberli I, Zimmermann MB (2011) Ten repeat collections for urinary iodine from spot samples or 24-hour samples are needed to reliably estimate individual iodine status in women. J Nutr 141(11):2049-2054

33. Andersen S, Pedersen KM, Pedersen IB, Laurberg P (2001) Variations in urinary iodine excretion and thyroid function. A 1-year study in healthy men. Eur J Endocrinol 144(5):461-465

34. Barr DB, Wilder LC, Caudill SP, Gonzalez AJ, Needham LL, Pirkle JL (2005) Urinary creatinine concentrations in the U.S. population: implications for urinary biologic monitoring measurements. Environ Health Perspect 113(2):192-200

35. Remer T, Neubert A, Maser-Gluth C (2002) Anthropometrybased reference values for 24-h urinary creatinine excretion during growth and their use in endocrine and nutritional research. Am J Clin Nutr 75(3):561-569

36. Johner SA, Thamm M, Nothlings U, Remer T (2013) Iodine status in preschool children and evaluation of major dietary iodine sources: a German experience. Eur J Nutr 52(7):1711-1719. doi:10.1007/s00394-012-0474-6

37. Bath SC, Nezianya CJ, Rayman MP (2015) A label-based assessment of the iodine content of milk-alternative drinks available in the UK. Proc Nutr Soc. In Press

38. Rose M, Miller P, Baxter M, Appleton G, Crews H, Croasdale M (2001) Bromine and iodine in 1997 UK total diet study samples. J Environ Monit 3(4):361-365

39. Andersen S, Karmisholt J, Pedersen KM, Laurberg P (2008) Reliability of studies of iodine intake and recommendations for number of samples in groups and in individuals. Br J Nutr 99(4):813-818

40. WHO (2014) Guideline: fortification of food-grade salt with iodine for the prevention and control of iodine deficiency disorders. World Health Organisation, Geneva

41. New Zealand Food Safety Authority (2009) The addition of folic acid and iodised salt to bread New Zealand. http://www.foodsafety.govt.nz/elibrary/industry/Addition_Folic-Manufacturers_ Retailers.pdf. Accessed 22 Feb 2012

42. Thomson CD, Colls AJ, Conaglen JV, Macormack M, Stiles M, Mann J (1997) Iodine status of New Zealand residents as assessed by urinary iodide excretion and thyroid hormones. Br J Nutr 78(6):901-912

43. Pettigrew-Porter A, Skeaff S, Gray A, Thomson C, Croxson M (2011) Are pregnant women in New Zealand iodine deficient? A cross-sectional survey. Aust N Z J Obstet Gynaecol 51(5):464-467

44. Food Standards Agency Australia and New Zealand (2009) Australian user guide mandatory iodine fortification. Implementing the requirements of mandatory fortification with iodised salt under standard 2.1.1 — cereals and cereal products. http://www. foodstandards.gov.au/foodstandards/userguides/mandatoryiodineforti4336.cfm. Accessed 22 Feb 2012

45. Australian Bureau of Statistics (2014) Australian Health Survey: biomedical results for nutrients, 2011-12; feature article: iodine. http://www.abs.gov.au/ausstats/abs@.nsf/Lookup/4364.0.55.006 Chapter1202011-12. Accessed 19 May 2015 